\title{
A Complex Adaptive Systems Approach to the Psychology of Political Change
}

\author{
Andrew Reilly \\ Research School of Psychology \\ The Australian National University \\ Canberra, Australia \\ andrew.reilly@anu.edu.au
}

\begin{abstract}
Psychological differences between individuals appear to play a role in political and social division, but process-based models of the relationship between personality and political orientation are lacking. Using a complex adaptive systems model, this paper argues that micro-level biological differences and macro-level sociocultural structures exert a bi-directional influence on personality as a meso-level construct. A processbased account of the relationship is provided, suggesting that initial biases at the biological level are accentuated through feedback effects that occur through social interactions. These individual differences drive collective adaptation to changing environments, resulting in the emergence of political values associated with successive phases of the adaptive cycle. Political and social division therefore occurs as an inevitable element in the process of societal adaptation and emerges out of interactions between individuals responding to stress. This flexible model is also able to account for both congruence and incongruence between personality and political orientation.
\end{abstract}

Keywords-political change; complex adaptive systems; psychology; personality; political values

\section{INTRODUCTION}

Social division has emerged as an issue facing many countries over the past 20 years. Populations are divided politically between liberals and conservatives, generationally between old and young, and geographically between urban and rural dwellers. Recent studies in political psychology suggest that these divisions may be partly due to psychological differences that predispose individuals to broad political orientations [1]. In particular, the epistemic, existential and relational motivations of individuals hold an affinity with positions available in a socially-constructed superstructure of political values and ideologies. However, the mechanisms by which individual differences contribute to the formation of ideologies and values, and how these reflexively shape individual preferences are unclear. Furthermore, the static nature of the relationships presented in this model limit its ability to account for the role of individual differences in social division and political change.

In this paper, I present a complex adaptive systems (CAS) perspective that offers a process-based model that can account for the relationship between individual differences and socially-constructed ideological positions, and the role this relationship plays in social division. In particular, I will focus on the five-factor model of personality, a common model in personality psychology, as an emergent, meso-level property of the interaction between micro-level biological systems and macro-level social systems. The five-factor model is based on accumulated evidence indicating that stable behavioural dispositions tend to reflect five common concerns when describing and evaluating people: social dominance, or extraversion; emotional stability, also referred to as neuroticism; a willingness to cooperate or get along with others, termed agreeableness; and openness to change, which includes cognitive flexibility and appreciation of novelty [2] [3].

\section{COMPLEX ADAPTIVE SYSTEMS THEORY}

Two dimensions can be used to define the actions of microlevel elements in CAS: connectivity and plasticity. Connectivity refers to the tendency of individual elements to form either local (low connectivity) or global (high connectivity) connections, while plasticity refers to the tendency for either making, breaking, or maintaining connections. Empirical studies have identified relationships between network structures with greater connectivity and plasticity, and loose personal networks made up of higherstatus individuals with more self-oriented goals. Associations between networks with lower connectivity and higher stability, and tighter personal networks made up of lower-status individuals have also been found. Other studies have also identified relationships between low status and the endorsement of conservative attitudes [4].

Order emerges in a CAS as it adapts to environmental conditions. For example, a particular configuration of relationships may be adapted to the environment in such a way that it offers some advantage or fitness to the elements involved. When environmental conditions change and elements find themselves maladapted to the new conditions, a period of instability results as the system explores new configurations that are more adaptive. A formal model of system adaptation is Holling's [5] four-phase adaptive cycle that can be applied to a broad, socio-political context. These phases include exploitation, a period of increasing fitness; conservation, a period of relative stability and resilience to change; release, a 
period of decreasing fitness; and reorganisation, a period of experimentation.

As the name suggests, a system undergoing exploitation has the ability to predict and respond to environmental events by structurally mapping them over time. The more plasticity a system has in forming connections, the more readily it can form adaptive structures and assimilate a greater variety of environmental events through its capacity to form both local and global connections, marking this phase as one of high connectivity. However, this increasing connectivity results in greater instability, as small changes in one area are more likely to spread across the network, resulting in feedback loops that can rapidly amplify minor disturbances [6]. For example, as political coalitions become more successful, it becomes more difficult to satisfy the conflicting demands of an increasing number of adherents, until any agreement made between two members inevitably impacts on those made with others, resulting in cascades of broken agreements [7]. Furthermore, environments inevitably change, despite the level of investment placed in existing structures, such that they outlive their usefulness, requiring greater levels of top-down control to maintain. Plasticity falls as individual elements struggle with the contradiction of maintaining current structures at increasing individual cost, and the longer this process of conservation continues, the higher the potential for a more catastrophic release phase. At this time, connectivity falls as local networks become more disconnected from each other and form groups that diverge as they follow their own trajectories [6].

However, this increasing diversity among groups allows the system as a whole to explore a greater variety of strategies, some of which will be more responsive than others to the changes that have occurred in the environment. As events associated with release wane and plasticity increases, elements enjoy greater freedom during the reorganisation phase to seek connections beyond local networks, providing the means for greater exploration, and thus the capacity to form new structures that afford exploitation. The ensuing period of growth, followed by increasing conservation, means that systems often experience extensive periods of stasis or mounting tension that are punctuated by shorter release events. However, as mentioned previously, systems do not always follow such a neat path, and phases may occur simultaneously at varying lengths and time scales according to their local conditions and systems boundaries [5]. Therefore, a CAS at a given level of analysis is often regarded as being in a constant state of adaptation, with ceaseless environmental change and strategy discovery consistently challenging the system's level of fitness. However, when multiple levels are considered, the complex, dynamic nature of CAS means that distinct phases of exploration and exploitation are rare, and instead, systems undergo multiple adaptive cycles simultaneously in different areas, time scales, and levels of abstraction. For example, the economy of a country may improve by reducing trade barriers that encourage new industries (increasing national economic fitness) that provide jobs for educated workers (increasing their individual fitness), while those in other industries may lose their jobs and struggle to find another (decreasing their individual fitness).

\section{APPLYING THE COMPLEX ADAPTIVE SYSTEMS APPROACH}

\section{A. Levels of Analysis}

The CAS model is one of multilevel emergence, where lower-order elements interact in such a way that higher-order macrostructures form with properties that cannot be reduced to the sum of the lower-order micro-level elements [8]. Thus causality between two levels of a system is bidirectional, as higher-order structures constrain the behaviour of the lowerorder elements from which they emerge. The boundaries between levels may be arbitrarily defined by researchers, but a common set of divisions found in the literature [9] can be determined in Figure 1.

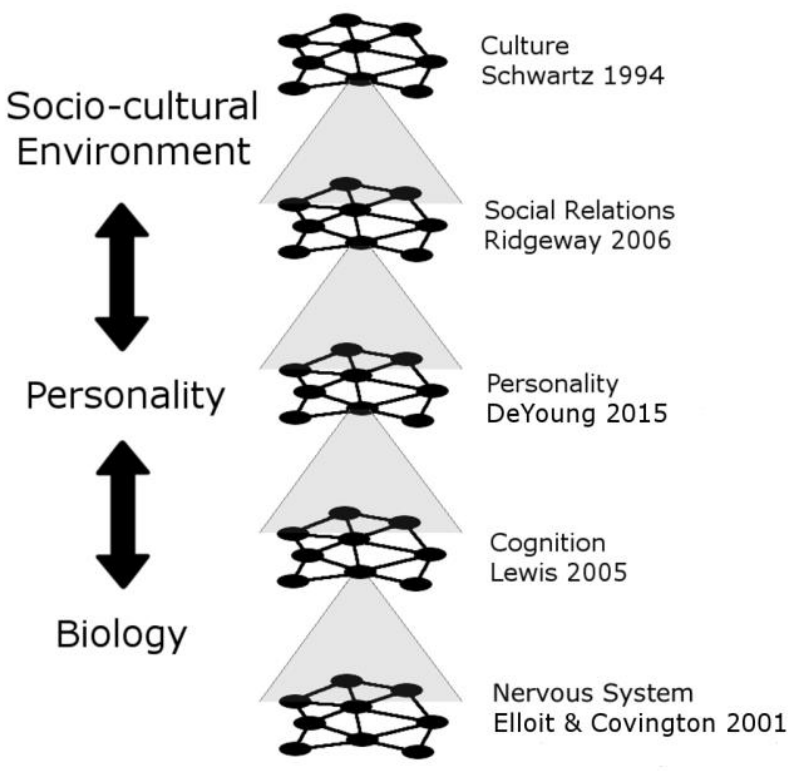

Figure 1. The hierarchy of systems where elements at each level emerge from interactions between elements in the level below, but are constrained by systems at higher levels.

At the lower level, biological structures associated with affiliation drive the personality system toward interactions with others so that many of the problems that confront the system are problems of social adaptation [10] where the behaviour of one individual provides the social environment of another [11] and responses seek to select, elicit or manipulate social situations [12]. This results in a dyadic relationship where individuals both shape and are shaped by each other, which bears its own unique behavioural signature, and thus its own "personality" emerging from the interaction between partners [11]. In combination, these relationships result in social networks with the formation of links biased towards relationships formed through successful adaptation based on shared cultural and interpersonal schemas [13], from which the socio-cultural system emerges. However, the immediate experience of an individual embedded in a social system is one where the socio-cultural system of shared values and ideologies is already present and reflects the accumulation of adaptive 
social structures adopted in the past. It is the rejection of this received structure that precipitates social and political change, and the probability of doing so is determined partly by the individual differences in the epistemic, existential and relational motivations of individuals.

In order to understand a given level fully, it is necessary to treat it as a meso-level phenomenon by examining both the level above, by which it is constrained, and the level below, from which it emerges [14]. Therefore, when examining personality, the CAS model can be applied at three levels of the emergent hierarchy: biology as a micro-level phenomenon, the sociocultural environment as a macrostructure, and the meeting of these in personality as a meso-level of interaction.

\section{B. Biology}

A key assumption of the CAS approach to personality is that constructs such as traits can be defined as biological and cognitive processes that occur over time. For example, repeated interactions between neurological elements as a learned response to particular stimuli may be reproduced, thus passing as stable features of a person's behaviour [15] that reflect accumulated adaptations to environmental changes [16]. Furthermore, these stable processes may contribute to, and be shaped by, the plasticity and stability of the social system.

1) Plasticity: The behavioural inhibition system (BIS) and behavioural activation system (BAS) manifest in a fundamental behavioural valency occurring even in very simple organisms based on the distinction between approach, where the organism moves towards a stimulus, and avoid, where it moves away [17] [18]. The approach orientation results from activity in the BAS, is motivated by the perception of novelty and potential reward, and is reflected in extraverted behaviours and positive emotions that are open to exploratory activities and the seizure of opportunities. The avoid orientation results from activity in the BIS, is motivated by the perception of negative or unwanted events and potential losses, and is reflected in behaviours associated with negative emotions and motivations to "play it safe" through the exploitation of familiar behaviours. For example, an event that does not match expectations may be perceived as a threat to personal fitness, activating the BIS and increasing subjective anxiety. This results in the exploration of behaviours that might alleviate the anxiety, and when this is successful, the BAS is activated, which increases approach motivation, exploiting the behaviour and thus reducing anxiety [19].

The success of the search depends on the availability of potential behaviours, and a greater range increases the probability of finding appropriate responses to a greater variety of situations. An essential element in providing this diversity is the default mode network (DMN) [20], a set of neuroanatomical areas that are activated independently of goaldirected behaviour [21] [22], that generates imaginative, creative and intellectual cognitions and is associated with the personality trait of openness to experience [23]. Therefore, individuals with a more active $\mathrm{DMN}$ are likely to play a greater role in generating alternative behaviours, responses and ideas that social systems need in order to adapt to a changing environment. Those with a less active DMN may develop more stable behavioural patterns and preferences, and may therefore contribute to the maintenance of existing, adaptive social structures, thus playing a role in the encoding and long-term stability of collective learning in the social system.

2) Connectivity: Fundamental biological drivers of relationships can be seen in neurological models of attachment where caregivers and infants become mutually entrained in synchronised cycles of opioid and norepinephrine depletion and replenishment [24]. Separation between infant and caregiver results in opioid depletion in the infant, which is experienced as subjective discomfort, accompanied by an increase in arousal through rising levels of norepinephrine, resulting in distress calls. On hearing these calls, a similar process occurs in the caregiver, who is then motivated to comfort the infant. This increases opioid levels in both the caregiver and infant, reducing subjective feelings of distress and levels of arousal. Although the infant eventually learns to self-regulate their own internal states, the synchronisation of separation and attachment phases between dyads characterises the nature of human relationships as tensions between individual and collective pursuits [24].

Individual differences in the regulation of attachment and separation at the biological level play a role in the formation of social networks, particularly when individuals across the network experience rising levels of stress [24]. For example, global, long-range ties tend to form as loosely-coupled dyads that are more likely to dissipate under stress when levels of oxytocin rise, resulting in increased sensitivity to gaps in social support. This response, termed tend-and-befriend, promotes behaviours associated with affiliation, such as seeking support through stronger ties offered by family and friends, and attending to their needs, particularly those of offspring [25]. Coupled with the familiar flight-or-fight response, with its focus on aggression and separation, these individual responses shape the collective response to stress in social networks by dissipating weak or outgroup ties, strengthening group boundaries and dividing the network into clusters.

\section{Sociocultural Environment}

At the individual level, human beings are concerned with their personal needs, while at the immediate social level they must coordinate their actions in meeting these needs with those on whom they depend, and who also depend on them in return, thus promoting the survival of oneself through the survival of the group [26]. Therefore people express themes associated with the attainment of these goals, resulting in the emergence of universal values associated with these themes, such that these values can be mapped back onto the adaptive challenges and behaviours that produce them. The adaptive cycle describes the phases of action and events that occur as human beings collectively face these challenges, and are therefore aligned with the values that are expressed as a results of this cyclical progression. However, it is important to note that each phase in the cycle occurs in response to the one preceding it, and both emerges out of and shapes the behaviours of individuals meeting challenges relevant to each phase.

Figure 2 summarises the work by Schwartz [26] [27] on universal human values reflecting themes associated with 
adaptation. Self-enhancement emphasises personal success and social dominance by valuing power, achievement and hedonism, indicating a willingness to make social connections based on exploitation of relationships and resources. Selftranscendence emphasises equality through social acceptance and concern, reflecting values such as benevolence, which encourages helpfulness, honesty and forgiveness; and universalism, which focuses on the understanding, appreciation, tolerance and protection of others. Benevolence has a stronger focus on face-to-face connections over universalism, but both are indicative of valuing social connections through concern for others rather than personal gain.

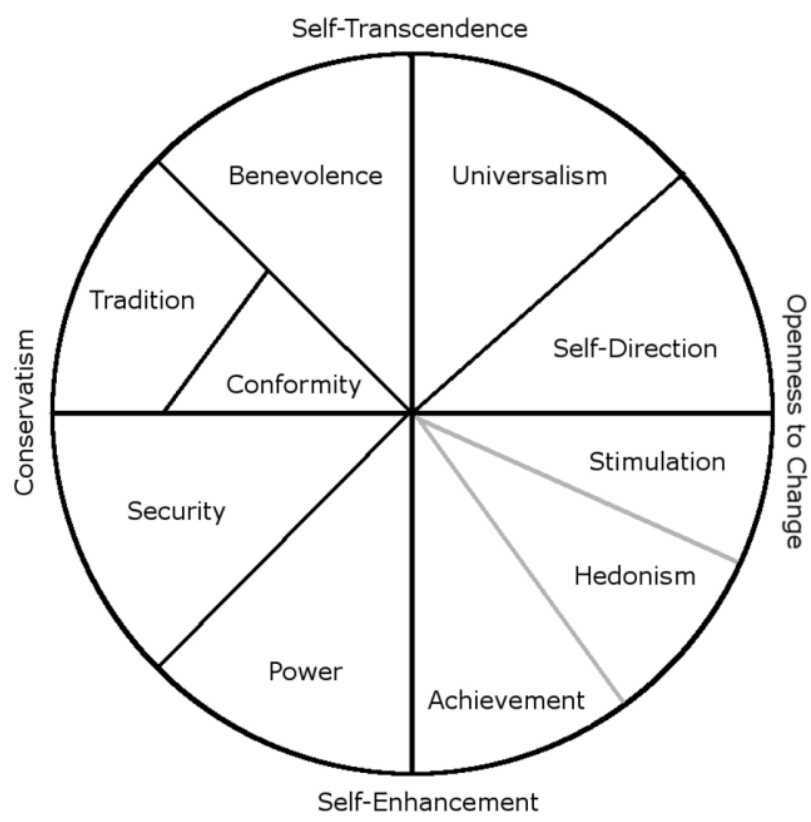

Figure 2. Circumplex of universal human values. Adapted from [26]

These common value dimensions are reflected in the phases of the adaptive cycle both as advocating for and responding to the trajectory of stasis, change and social organisation in human societies. For this reason, political issues serve as indicators of challenges posed by particular phases, and personality traits reflect stable adaptive strategies in meeting those challenges. This is reflected in the pattern of relationships between these values, big five personality traits [28] and positions on political issues displayed in Table 1.

Release events occur in social systems when individuals refuse or are unable to continue engaging in actions that reproduce existing social structures. However, such phases in the adaptive cycle rarely occur as discrete incidents [5], and each emerges out of the previous phase. Therefore, the release phase occurs as a result of the contradictions that accumulate in the exploitation phase [29] and begins during the conservation phase. At this time, the social system responds to increasing stress through the dissolution of global, long-range links and the strengthening of local connections, smaller groups and tighter boundaries [6], resulting in concurrent higher-level divisions between groups and increased lower-level density within groups. For example, economic stress may result in political fragmentation and the emergence of new political parties, but within these parties this process is one of increasing membership and greater political cooperation.

This transition from conservation to release is marked by a change in behaviour and preferences associated with benevolence over tradition and conformity. As can be seen in Table 1, benevolence is associated with higher levels of agreeableness as individuals prioritise local, face-to-face relationships and relax social conventions associated with traditional morality, patriotism and legal structures. This inevitably undermines the existing social hierarchy, to the point where elites no longer command the respect they once did, and there is an increased focus on equality and the rights of individuals through civil liberties. As this process continues and the pressures that triggered the release phase begin to ease, increasing local interdependence puts pressure on group boundaries, increasing group size, and the expression of values and behaviours associated with universalism. This can be seen in the positive relationship between universalism and openness, stronger negative relationships with positions reflecting the status quo, and positive relationships with positions reflecting equality, including greater acceptance of immigrants.

As with the release phase, the reorganisation phase has its roots in previous phases. Social structures are reformed in response to the faults of the exploitation and conservation phases that precipitated the release phase. Values associated with benevolence and universalism in the release phase, such as concerns for the welfare of others and the nurturing of equal opportunities, ultimately provide a foundation for increased self-direction and greater personal freedom. This can be seen in the stronger relationships between self-direction and openness and the negative relationships between self-direction and traditional morality, patriotism, legal structures and the military, while individual freedoms and openness to alternative perspectives can be seen in the positive relationships between self-direction and civil liberties and immigration.

The values of self-direction, such as creativity, curiosity and freedom, promote the kind of experimentation, pursuit of novelty and creativity that drives the reorganisation phase [30] When these experiments and creative pursuits result in higher levels of fitness, whether that be social, cultural or economic, individuals are rewarded and encouraged to actively pursue advantageous solutions to problems. This can be seen in positive relationships between values associated with stimulation and both openness and extraversion, and greater indifference to the kind of risks and gains associated with free enterprise, as evidenced by a lack of a relationship between free enterprise and stimulation. A similar pattern of relationships can also be identified with values associated with hedonism, as personal reward begins to be favoured over concerns with equality and the kind of selflessness associated with the acceptance of immigrants. 
TABLE I. STATISTICAL RELATIONSHIPS BETWEEN UNIVERSAL VALUES, BIG FIVE PERSONALITY TRAITS AND POSITIONS ON POLITICAL ISSUES

\begin{tabular}{|c|c|c|c|c|c|c|c|c|c|c|}
\hline \multirow{2}{*}{$\begin{array}{l}\text { Phase } \\
\text { Value } \dagger\end{array}$} & \multicolumn{2}{|c|}{ Release } & \multicolumn{3}{|c|}{ Reorganisation } & \multicolumn{2}{|c|}{ Exploitation } & \multicolumn{3}{|c|}{ Conservation } \\
\hline & $B$ & $U$ & $S D$ & $S T$ & $H$ & $A$ & $P$ & $S$ & $C$ & $T$ \\
\hline Agreeableness $^{\mathrm{a}}$ & .61 & .39 & & & & & -.42 & & .26 & .22 \\
\hline Openness $^{\mathrm{a}}$ & & .33 & .52 & .36 & & & & -.24 & -.27 & -.31 \\
\hline Conscientiousness $^{\mathrm{a}}$ & & & & & & .17 & & .37 & .27 & \\
\hline Extraversion $^{\mathrm{a}}$ & & & & .36 & .20 & .31 & .31 & & & \\
\hline Traditional Morality $^{\mathrm{b}}$ & & $-.19^{* *}$ & $-.38^{* *}$ & $-.40^{* *}$ & $-.36^{* *}$ & $-.15^{* *}$ & $-.07 *$ & $.48^{* *}$ & $.45^{* *}$ & $.53^{* *}$ \\
\hline Blind Patriotism ${ }^{\mathrm{b}}$ & $-.12^{* *}$ & $-.27^{* *}$ & $-.34 * *$ & $-.28^{* *}$ & $-.25^{* *}$ & & & $.43^{* *}$ & $.35^{* *}$ & $.37 * *$ \\
\hline Law \& Order ${ }^{b}$ & $-.20 * *$ & $-.33^{* *}$ & $-.30 * *$ & $-.23 * *$ & $-.21 * *$ & & $.12^{* *}$ & $.39^{* *}$ & $.30^{* *}$ & $.32 * *$ \\
\hline Military Intervention ${ }^{\mathrm{b}}$ & $-.24 * *$ & $-.40^{* *}$ & $-.21 * *$ & $-.14 * *$ & $-.11^{* *}$ & $.11^{* *}$ & $.23^{* *}$ & $.30^{* *}$ & $.21^{* *}$ & $.20 * *$ \\
\hline Free Enterprise $^{b}$ & $-.20^{* *}$ & $-.39^{* *}$ & $-.17 * *$ & & & $.14^{* *}$ & $.27 * *$ & $.15^{* *}$ & $.12 * *$ & $.14^{* *}$ \\
\hline Equality $^{\mathrm{b}}$ & $.23 * *$ & $.43^{* *}$ & & $-.07^{*}$ & $-.08^{*}$ & $-.19 * *$ & $-.33^{* *}$ & & & \\
\hline Civil Liberties $^{\mathrm{b}}$ & $.18^{* *}$ & $.32^{* *}$ & $.19^{* *}$ & & & $-.11 * *$ & $-.26^{* *}$ & $-.08^{*}$ & $-.08^{*}$ & $-.21 * *$ \\
\hline Accepting Immigrants ${ }^{\mathrm{b}}$ & $.20^{* *}$ & $.36^{* *}$ & $.25^{* *}$ & $.23^{* *}$ & $.09^{* *}$ & & $-.08^{*}$ & $-.37^{* *}$ & $-.27^{* *}$ & $-.26^{* *}$ \\
\hline
\end{tabular}

a. Meta-analysis summary values for $\rho$ where the $80 \%$ credibility value does not include 0 [32]

b Values indicate $r[33]$

${ }^{*} \mathrm{p}<.01, * * \mathrm{p}<.001$

$\dagger \mathrm{B}=$ Benevolence, $\mathrm{U}=$ Universalism, $\mathrm{SD}=$ Self-Direction, $\mathrm{ST}=$ Stimulation, $\mathrm{H}=$ Hedonism, $\mathrm{A}=$ Achievement, $\mathrm{P}=$ Power, $\mathrm{S}=$ Security, $\mathrm{C}=$ Conformity, $\mathrm{T}=$ Tradition

The transition from the reorganisation phase to the exploitation phase also marks a broader switch from exploration to exploitation that indicates a pivotal point of adaptation, where CAS are judged to have adapted successfully to change. The willingness to identify and seize opportunities that have become available as a result of the innovations that emerged during the reorganisation phase is associated with extraversion, and this can be seen in positive relationships between extraversion and stimulation, hedonism, achievement and power. Furthermore, extraverted individuals are more likely to seek out social connections that transcend group boundaries [31], which results in an increase in connectivity across social networks. These global, long-range connections are driven by the opportunities they provide for personal gain rather than values associated with selflessness, which are increasingly seen as a drag on ambition. Therefore, negative relationships can be seen between ambition and power, equality and civil liberties, and positive relationships with free enterprise.

The reorganisation and exploitation phases result in the rebuilding of social structures that are more resilient to changes in the environment than previous structures that were dismantled during the release stage. However, these new structures have flaws of their own, and changes to the environment over time challenge their ability to respond as adaptively as they once did. Furthermore, as people are now invested in these structures, their loss represents a threat, and so measures are taken to preserve them, resulting in a period of conservation. This can be seen in negative relationships between security, conformity and tradition with openness to experience, and also with positions representing the maintenance of the status quo, such as traditional morality, patriotism and law and order, while concerns with individual liberty are apparent in the negative relationship between tradition and civil liberties.

However, this stability also allows feedback loops to remain in place, strengthening structures that may no longer be as effective as they once were and resulting in increasing extremes, for example when inequality rises as resources accumulate to fewer and fewer people [34]. As increasing connectivity results in greater instability and vulnerability to external shocks [6] from an environment that continues to change, the increasing vulnerability of the system exposes individuals to insecurity and instability, which in turn, motivates those who are sensitive to threat and fearful of losing the gains acquired during the exploitation phase to clamp down on dissent and alternative views. Over time, this tension mounts, and paves the way for the next release phase.

\section{Personality}

We come now to the complex task of understanding the interaction between biological and socio-cultural systems from which personality emerges. To begin with, differences in genetic inheritance bias the expression of personality type [34] so that individuals possess subtle preferences reflected in behavioural responses associated with openness to experience [35], for example, through a more active DMN [23]. The dynamic interplay between biological system elements such as the DMN and the BIS/BAS occurs as self-regulating cycles [36], such that stable patterns of interaction emerge as adaptive 
behavioural responses [37]. This system exhibits rudimentary behaviours aligned with the big five personality traits, with extraversion and openness to experience contributing to plasticity, and conscientiousness, agreeableness and neuroticism determining stability [16]. These relatively stable processes are developed and constrained through feedback effects. For example, extraverted individuals are more likely to initiate relationships [38], occupy central positions in team networks [39] and attain higher status [40], but these are all structural positions that result in situations for which extraversion is advantageous. A tendency to initiate relationships will inevitably result in the acquisition of multiple relationships, which increases the probability of occupying a central position in a social network, which encourages the kind of social skills that confer status, which attracts others. Thus an early tendency to extraversion biases individuals towards situations where extraverted behaviour is rewarded.

This top-down, bottom-up model of personality development provides a broad schema for the relationship between low-level individual tendencies and preferences and higher-level social structures like political ideologies. For example, individuals inclined to greater activation of the BAS in response to expectancy violation [19] have stronger tendencies to action for the purposes of maintaining order and resolving discrepancy. In a social environment materially or culturally invested in the maintenance and exploitation of existing social structures, this behaviour is more likely to be rewarded, resulting in the accumulation of deeply-ingrained cognitive schemas promoting existing political structures, which in turn, reinforces the continuation of actions designed to eliminate opposition threatening perceived disorder [41]. As environmental changes strain existing social structures, and discrepancies between expectation and reality become more apparent, anxiety increases among diverse individuals, who respond by reaching out to those with whom they perceive a common cause. Those for whom an under-stimulated DMN offers few alternatives, those inclined to action through an over-stimulated BAS, and those with a strong tendency for affiliation when stressed may then become mutually entrained in a social network of codependence, from which causes, narratives, justifications and explanations emerge, further reinforcing any existing beliefs as a bulwark against anxiety in the face of change. The inevitable outcome of this process is the formation of tighter social groups with less permeable boundaries, as the mutual exchange of affirmative beliefs serves to relieve the anxiety experienced when exposed to alternatives that lie beyond the immediate social group. In contrast, those with a more active DMN are able to access a greater range of alternative responses and imagine these as potential futures, and as a result, are less likely to experience anxiety in relation to change. In an environment where arrangements no longer provide the returns they once did, these alternatives become increasingly attractive among those who perceive that there is little to be lost. When anxiety over this precarious state drives affiliative responses, group-formation occurs again, separating those advocating alternatives to the status quo from those who fear its demise. This increasing isolation between social groups results in a loss of connectivity across the social network, indicating characteristics of the release phase that eventually result in greater diversity as disparate groups go their own way in supporting the status quo or exploring alternatives, which inevitably leads to the reorganisation phase.

This example shows how bottom-up diversity in genetic inheritance that may incline an individual to say, a more active $\mathrm{DMN}$, and top-down dynamics of a social system adapting to its environment, interact in the co-constitution of cognitiveaffective structures and interpersonal relationships. Thus it is not simply that a particular individual self-identifies as a conservative due to an under-responsive DMN, but that the interaction between this tendency and specific features of the social context are such that the individual has adapted to their environment by adopting conservative positions as a solution to the cognitive, emotional and social challenges they have faced [1]. Furthermore, given that each phase of the adaptive cycle both results from and appeals to the inclinations of different individuals, and that each phase occurs as the inevitable outcome of the phase preceding it, a complex model of the long-term development of personality emerges where personality is not only co-constituted by the interplay between biology and sociocultural influence, but is a reflection of common approaches taken when adapting to social circumstances during successive phases of the adaptive cycle to which individuals living at different times may be attuned. It is important at this point to recognise that for many people, biological preferences may not be particularly strong, but that the affinity for a particular phase held by those with stronger preferences is so acute that they hold an advantage in persuading those without strong preferences over those with preferences that are not attuned to the current phase.

Therefore, in this example, individuals seek to carve out a niche for themselves in a changing social structure that satisfies their existential, epistemic and relational needs, but in doing so, they contribute to structural change that is occurring. For this reason, it may often be the case that individuals who score highly on openness to experience also express support for liberal political positions, but those that do not may have developed a niche within the sociopolitical structure where it has been advantageous to perform behaviours related to openness to experience in support of a conservative political position. For example, in late 1970s Britain, advocating freemarket economics was an alternative course of action that went against decades of economic policy, despite the fact that it was a formal position of the Conservative party.

\section{E. Conclusion}

The CAS perspective allows for a number of tentative conclusions to be drawn. Firstly, that human behaviour resulting in social division can be seen as an adaptive response to increasing anxiety. Furthermore, social change occurs not as an event, but as a process of interactions between individuals adapting to their immediate circumstances that exerts a cumulative force driving the social system through inevitable phases, each of which emerges inevitably and continuously from the one before. Therefore, questions regarding how and why people with particular preferences are attracted to certain political ideologies, or why they identify with one group more than another can be addressed by examining the trajectory of the social system as a whole through the social and 
psychological interactions that facilitate adaptation and drive the system inexorably into the next phase.

\section{REFERENCES}

[1] J. T. Jost, C. M. Federico, and J. L. Napier, "Political Ideology: Its Structure, Functions, and Elective Affinities," Annu. Rev. Psychol., vol. 60, no. 1, pp. 307-337, 2009.

[2] L. R. Goldberg, "Language and individual differences: The search for universals in personality lexicons," Pers. Soc. Psychol. Rev., vol. 2, no. 1, pp. 141-165, 1981.

[3] R. R. McCrae and P. T. Costa Jr., "McCrae - The five-factor theory of personality.pdf," in Handbook of Personality: Theory and Research, $\mathrm{O}$. P. John, L. A. Pervin, and R. W. Robins, Eds. New York: Guilford Publications, 2008, pp. 159-181.

[4] H. R. Markus and N. M. Stephens, "Editorial overview: Inequality and social class: The psychological and behavioral consequences of inequality and social class: a theoretical integration," Curr Opin Psychol, vol. 18, pp. iv-xii, Dec. 2017.

[5] C. S. Holling, "Understanding the Complexity of Economic, Ecological, and Social Systems," Ecosystems, vol. 4, no. 5, pp. 390-405, Aug. 2001.

[6] G. Paperin, D. G. Green, and S. Sadedin, "Dual-phase evolution in complex adaptive systems," J. R. Soc. Interface, vol. 8, no. 58, pp. 609629, May 2011.

[7] G. G. Brunk, "Self-Organized Criticality: A New Theory of Political Behaviour and Some of Its Implications," Br. J. Polit. Sci., vol. 31, no. 2, pp. 427-445, Apr. 2001.

[8] M. Mitchell, Complexity: A Guided Tour. Oxford University Press, 2009.

[9] K. M. Sheldon, C. Cheng, and J. Hilpert, "Understanding Well-Being and Optimal Functioning: Applying the Multilevel Personality in Context (MPIC) Model," Psychol. Inq., vol. 22, no. 1, pp. 1-16, Feb. 2011.

[10] D. M. Buss, "An evolutionary formulation of person-situation interactions," J. Res. Pers., vol. 43, no. 2, pp. 241-242, Apr. 2009.

[11] Y. Shoda and S. LeeTiernan, "Personality as a dynamical system: Emergence of stability and distinctiveness from intra and interpersonal interactions," Pers. Soc. Psychol. Rev., 2002.

[12] D. M. Buss, "Selection, evocation, and manipulation," J. Pers. Soc. Psychol., vol. 53, no. 6, pp. 1214-1221, Dec. 1987.

[13] Cecilia L. Ridgeway, "Linking Social Structure and Interpersonal Behavior: A Theoretical Perspective on Cultural Schemas and Social Relations," Soc. Psychol. Q., vol. 69, no. 1, pp. 5-16, Mar. 2006.

[14] P. Anderson et al., "Understanding mechanisms in organisational research," Journal of Management Inquiry, vol. 15, no. 2, pp. 102-113, 2006.

[15] M. Fajkowska, "The Complex-System Approach to Personality: Main theoretical assumptions," J. Res. Pers., vol. 56, pp. 15-32, 2015.

[16] C. G. DeYoung, "Cybernetic Big Five Theory," J. Res. Pers., vol. 56, pp. 33-58, 2015.

[17] A. J. Elliot and M. V. Covington, "Approach and Avoidance Motivation,” Educ. Psychol. Rev., vol. 13, no. 2, pp. 73-92, Jun. 2001.

[18] A. J. Elliot and T. M. Thrash, "Approach-avoidance motivation in personality: Approach and avoidance temperaments and goals," J. Pers. Soc. Psychol., vol. 82, no. 5, pp. 804-818, 2002.

[19] S. M. Tritt, M. Inzlicht, and E. Harmon-jones, "Toward a biological understanding of mortality salience (and other threat compensation processes)," Social Cognition, vol. 30, no. 6, pp. 715-733, 2012.

[20] L. Q. Uddin, A. M. Kelly, B. B. Biswal, F. X. Castellanos, and M. P. Milham, "Functional connectivity of default mode network components: correlation, anticorrelation, and causality," Hum. Brain Mapp., vol. 30, no. 2, pp. 625-637, Feb. 2009.

[21] M. E. Raichle and A. Z. Snyder, "A default mode of brain function: a brief history of an evolving idea," Neuroimage, vol. 37, no. 4, pp. 108390; discussion 1097-9, Oct. 2007.
[22] M. E. Raichle, A. M. MacLeod, A. Z. Snyder, W. J. Powers, D. A. Gusnard, and G. L. Shulman, "A default mode of brain function," Proc. Natl. Acad. Sci. U. S. A., vol. 98, no. 2, pp. 676-682, Jan. 2001.

[23] R. E. Beaty et al., "Personality and complex brain networks: The role of openness to experience in default network efficiency," Hum. Brain Mapp., vol. 37, no. 2, pp. 773-779, Feb. 2016.

[24] T. S. Smith, "Attachment, Interaction, and Synchronization: How Innate Mechanisms in Attachment Give Rise to Emergent Structure in Networks and Communities," in Handbook of Neurosociology, D. D. Franks and J. H. Turner, Eds. Dordrecht: Springer Netherlands, 2013, pp. 243-254.

[25] S. E. Taylor, "Tend and Befriend: Biobehavioral Bases of Affiliation under Stress," Curr. Dir. Psychol. Sci., vol. 15, no. 6, pp. 273-277, 2006.

[26] S. Schwartz, "Are there universal aspects in the structure and contents of human values?," J. Soc. Issues, vol. 4, pp. 19-45, 1994.

[27] S. H. Schwartz and W. Bilsky, "Toward A Universal Psychological Structure of Human Values," Journal of Personality and Social Psychology, vol. 53, no. 3, pp. 550-562, 1987.

[28] L. Parks-Leduc, G. Feldman, and A. Bardi, "Personality traits and personal values: a meta-analysis," Pers. Soc. Psychol. Rev., vol. 19, no. 1, pp. 3-29, Feb. 2015.

[29] G. Cumming and J. Collier, "Change and Identity in Complex Systems," Ecol. Soc., vol. 10, no. 1, Jun. 2005.

[30] C. S. Holling, "From Complex Regions to Complex Worlds," Ecol. Soc., vol. 9, no. 1, Mar. 2004.

[31] R. N. Turner, K. Dhont, M. Hewstone, A. Prestwich, and C. Vonofakou, "The Role of Personality Factors in the Reduction of Intergroup Anxiety and Amelioration of Outgroup Attitudes via Intergroup Contact: Contact and personality predictors," Eur. J. Pers., vol. 28, no. 2, pp. 180-192, Mar. 2014.

[32] L. Parks-Leduc, G. Feldman, and A. Bardi, "Personality traits and personal values: a meta-analysis," Pers. Soc. Psychol. Rev., vol. 19, no. 1, pp. 3-29, Feb. 2015.

[33] S. H. Schwartz, G. V. Caprara, and M. Vecchione, "Basic Personal Values, Core Political Values, and Voting: A Longitudinal Analysis," Polit. Psychol., vol. 31, no. 3, pp. 421-452, Jun. 2010.

[34] D. J. Davidson, "The applicability of the concept of resilience to social systems: Some sources of optimism and nagging doubts" Society and Natural Resources, vol. 23, no. 12, pp. 1135-1149, Aug. 2010.

[35] D. Réale and N. J. Dingemanse, "Personality and individual social specialisation," Social behaviour: genes, ecology and evolution, 2010.

[36] T. Vukasović and D. Bratko, "Heritability of personality: A metaanalysis of behavior genetic studies," Psychol. Bull., vol. 141, no. 4, pp. 769-785, Jul. 2015.

[37] M. D. Lewis, "Bridging emotion theory and neurobiology through dynamic systems modeling," Behav. Brain Sci., vol. 28, no. 2, pp. 16994; discussion 194-245, Apr. 2005.

[38] A. O. J. Cramer et al., "Dimensions of Normal Personality as Networks in Search of Equilibrium: You Can't Like Parties if You Don't Like People," Eur. J. Pers., vol. 26, no. 4, pp. 414-431, Jul. 2012.

[39] M. Selfhout, W. Burk, S. Branje, J. Denissen, M. van Aken, and W. Meeus, "Emerging Late Adolescent Friendship Networks and Big Five Personality Traits: A Social Network Approach,” J. Pers., vol. 78, no. 2, pp. 509-538, 2010.

[40] K. J. Klein, B.-C. Lim, J. L. Saltz, and D. M. Mayer, "How do they get there? An examination of the antecedents of centrality in team networks," Acad. Manage. J., vol. 47, no. 6, pp. 952-963, 2004.

[41] C. Anderson and J. Cowan, "Personality and Status Attainment: A Micropolitics Perspective," in The Psychology of Social Status, J. T. Cheng, J. L. Tracy, and C. Anderson, Eds. New York, NY: Springer New York, 2014, pp. 99-117.

[42] J. T. Jost, A. Ledgerwood, and C. D. Hardin, "Shared Reality, System Justification, and the Relational Basis of Ideological Beliefs," Soc. Personal. Psychol. Compass, vol. 2, no. 1, pp. 171-186, Jan. 2008. 